\title{
NMR-Enhanced Crystallography Aids Open Metal-Organic Framework Discovery Using Solvent-Free Accelerated Aging
}

\author{
Christopher A. O’Keefe, ${ }^{a, \dagger}$ Cristina Mottillo, ${ }^{b}$ Jogirdas Vainauskas, ${ }^{b}$ László Fábián, ${ }^{c}$ Tomislav \\ Friščić ${ }^{b, *}$ and Robert W. Schurko ${ }^{a, d, *}$
}

${ }^{a}$ Department of Chemistry and Biochemistry, University of Windsor, Windsor, ON, Canada, N9B 3P4; ${ }^{b}$ Department of Chemistry, McGill University, Montreal, QC, Canada, H3A 0B8; cSchool of Pharmacy, University of East Anglia, Norwich, UK, NR4 7TJ; ${ }^{d}$ Department of Chemistry and Biochemistry, Florida State University, Tallahassee, FL, 32308.

\begin{abstract}
We demonstrate the combined use of NMR-enhanced crystallography and solvent-free synthesis by accelerated aging (AA), for the discovery and structural characterization of a novel cadmium-based open metal-organic framework belonging to the class of zeolitic imidazolate frameworks (ZIFs). Whereas solid-state NMR spectroscopy has been used to assist in structural characterization of crystalline solids by powder X-ray diffraction (PXRD), typically through quantification of the contents of the asymmetric unit, this work highlights how it can take a more active role in guiding structure determination, by elucidating the coordination environment of the metal node in a novel metal-organic framework. Exploration of AA reactions of cadmium oxide ( $\mathrm{CdO}$ ) and 2-methylimidazole (HMeIm) enabled the synthesis of the previously reported yqt1-topology framework, but also a new material (1) exhibiting a Cd:MeIm ratio of 1:3, contrasting the 1:2 ratio expected for a ZIF. Structural characterization of $\mathbf{1}$ was enabled by using ${ }^{111} \mathrm{Cd}$ solid-state nuclear magnetic resonance (SSNMR) to provide information on the coordination environment of the cadmium node. Specifically, ${ }^{111} \mathrm{Cd}$ SSNMR experiments were conducted on a series of model compounds to correlate the cadmium coordination environment to the observed isotropic chemical shift, $\delta_{\text {iso }}\left({ }^{111} \mathrm{Cd}\right)$, followed by multinuclear SSNMR experiments on $\mathbf{1}$ to determine the nature of the metal coordination environment and the number of distinct chemical sites. This information was used in refinement of the molecular-level structure from the available powder X-ray diffraction data, a technique termed NMR-enhanced crystallography, revealing that $\mathbf{1}$ is an open diamondoid (dia) topology $\mathrm{Cd}(\mathbf{M e I m})_{2}$ framework based on $\mathrm{Cd}^{2+}$ ions tetrahedrally coordinated with MeIm- ligands, and additional HMeIm guest molecules within the framework pores. Whereas accelerated aging was initially devised as a clean, mild route for making MOFs, these results provide a proof-of-principle of how, by combining it with SSNMR spectroscopy as a means to overcome limitations of PXRD structure determination, it can be used to screen for new solid phases in the absence of solvents, high temperatures or mechanical impact that are inherent to other thermally-, solution- or mechanochemicallybased techniques.
\end{abstract}

\section{Introduction}

Metal-organic frameworks (MOFs) ${ }^{1,2}$ represent a rapidly developing class of materials with proposed applications in many fields. ${ }^{3-9}$ Recent commercialization and anticipated large-scale ${ }^{10-12}$ use of MOFs have highlighted the need for simpler, cleaner synthetic routes, and efficient techniques to screen the landscape of possible open MOF phases in order to clearly understand the factors contributing to their formation and stability. ${ }^{13-15}$ Solvent-free reactions are promising in both contexts by enabling both clean syntheses directly from metal oxides or carbonates and discovery of new phases - even in systems that have been well studied. ${ }^{16}$ One example of a solvent-free technique is accelerated aging (AA), a recently developed simple, solvent-free, lowenergy synthetic technique inspired by naturally occurring spontaneous mineral neogenesis processes. ${ }^{17}$ The principal aim of AA is to enable chemical synthesis utilizing minimum amounts of the simplest available reactants under low-energy conditions (i.e., moderate temperatures and high humidity). The methodology is based on promoting reactivity in static mixtures of suitable reactants, typically minerallike metal oxides or carbonates, by exposure to high relative humidity (RH) and/or addition of catalytic or structure- templating salt additives. So far, AA has been used to generate several commercially relevant MOFs, including Zn- and Co(II)-based zeolitic imidazolate frameworks (ZIFs), ${ }^{18-20}$ and zirconium-based $\mathrm{UiO}$ systems. ${ }^{21}$

Solid-state NMR (SSNMR) spectroscopy is a powerful technique for providing molecular-level information on the structure and dynamics of solids. It is well-suited to studies of both ordered and disordered materials, ${ }^{22-24}$ providing valuable information on short-range order. NMR-enhanced crystallography combines information on local structure (SSNMR) with details on long-range order (powder X-ray diffraction, PXRD) for elucidating structures of solids. ${ }^{25,26}$ While SSNMR has been used to study crystalline or amorphous MOFs and guest inclusion, ${ }^{27-38}$ there have been relatively few reports of the elucidation of the full structure of MOF using NMR. ${ }^{39,40}$ Importantly, the role of NMR spectroscopy in structural characterization of new organic or metalorganic materials is typically limited to quantification of the contents of the asymmetric unit, specifically determination of $Z^{\prime}$ (i.e., the number of molecules in the asymmetric unit). ${ }^{41-45}$

Whereas the principal goal of AA is minimalistic synthesis, here we show that it also offers an opportunity to 
discover new open-framework materials. We have used multinuclear SSNMR to guide PXRD structure solution for a novel open-framework ZIF (1) of diamondoid (dia) topology, discovered while investigating an AA synthesis of ZIFs from $\mathrm{CdO}$ and 2-methylimidazole (HMeIm, Scheme 1). The role of SSNMR in this process is much more active than typically encountered, as it provided a direct way to spectroscopically determine the coordination geometry of the framework nodes.

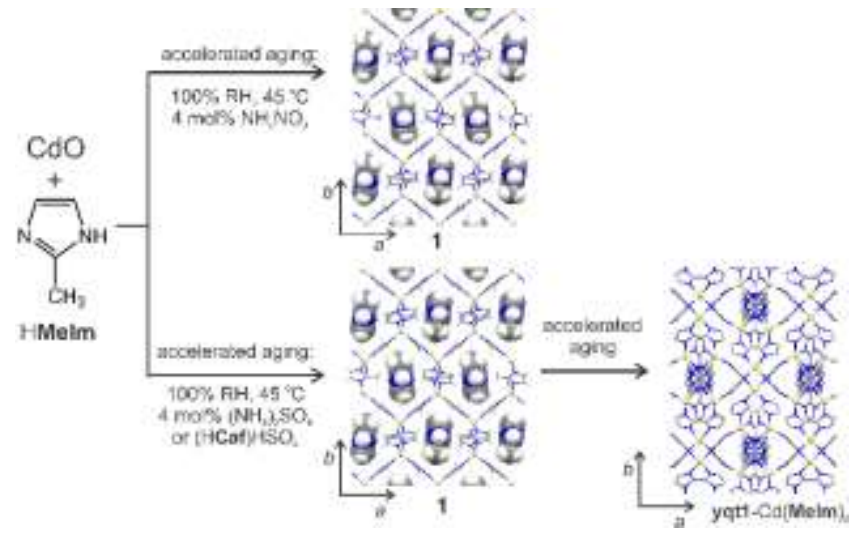

Scheme 1. Accelerated aging (AA) reactivity of $\mathrm{CdO}$ and HMeIm in the presence of catalytic amounts $(4 \mathrm{~mol} \%$ with respect to the metal) of selected ammonium salts leads to the formation of a novel dia-topology phase (1), whose structural characterization was enabled by NMR-enhanced crystallography. The dia-phase $\mathbf{1}$ was either the final product (with $\mathrm{NH}_{4} \mathrm{NO}_{3}$ as the AA additive) or an intermediate towards yqt1$\mathrm{Cd}(\mathbf{M e I m})_{2}$ framework (CCDC code GUPBOJ) (with $\left(\mathrm{NH}_{4}\right)_{2} \mathrm{SO}_{4}$ or $\mathrm{HCafHSO}_{4}$ as an additive).

The discovery of $\mathbf{1}$ is notable, as the $\mathrm{Cd}(\mathbf{M e I m})_{2}$ system is well-investigated, with several MOFs of SOD, MER, yqt1, ict, and RHO topologies reported since 2010.46-48 As direct structural solution of $\mathbf{1}$ from PXRD data ${ }^{49}$ was complicated by an unexpected and unusual 1:3 ratio of metal to ligand, its discovery and structural characterization followed this series of steps: (i) discovery of the new phase and evaluation of metal:HMeIm ratio using PXRD analysis, (ii) establishing correlations between the Cd chemical shift (CS) tensor parameters and $\mathrm{Cd}$ coordination environments via ${ }^{111} \mathrm{Cd}$ SSNMR of reference materials, (iii) determination of the $\mathrm{Cd}^{2+}$ coordination environment in 1 via ${ }^{111} \mathrm{Cd}$ SSNMR, (iv) examination of HMeIm speciation by multinuclear $\left({ }^{1} \mathrm{H},{ }^{13} \mathrm{C}\right.$, and ${ }^{14} \mathrm{~N}$ ) SSNMR of 1, and ( $v$ ) NMR-directed structural solution and refinement of the PXRD data.

\section{Experimental details}

Reagents. Cadmium oxide (CdO), 2-methylimidazole (HMeIm), imidazole (HIm), ammonium nitrate $\left(\mathrm{NH}_{4} \mathrm{NO}_{3}\right)$, and ammonium sulphate $\left(\left(\mathrm{NH}_{4}\right)_{2} \mathrm{SO}_{4}\right)$ were purchased from Sigma-Aldrich and used without further purification. Caffeinium hydrogensulfate $\left(\mathrm{HCafHSO}_{4}\right)$ was synthesized based on a previously described procedure. ${ }^{20}$

Accelerated Aging (AA). In a typical reaction, the reactants were milled on a one-gram scale in the pre-determined stoichiometric ratio using a Retsch MM400 ball mill to produce a homogeneous mixture. Milling was done for 5 minutes at $30 \mathrm{~Hz}$, using a $10 \mathrm{~mL}$ volume stainless steel milling jar equipped with two $7 \mathrm{~mm}$ diameter (1.3 g weight each) stainless steel balls. The resulting mixtures were analyzed by PXRD, and placed in an acrylic hydration chamber maintained at $100 \% \mathrm{RH}$ and $45^{\circ} \mathrm{C}$. Progress of AA reactions was followed by periodically removing a small fraction of each sample for analysis by PXRD. Samples in which there was no remaining $\mathrm{CdO}$ and for which the product consisted of one pure crystalline product were washed in $\mathrm{MeOH}$ overnight and dried in vacuo at $80{ }^{\circ} \mathrm{C}$ overnight prior to further solidstate analysis (PXRD, TGA, FTIR-ATR).

Synthesis of dia-Cd(MeIm) $2 \cdot$ HMeIm (1): A 1:3 stoichiometric mixture of CdO ( $2 \mathrm{mmol}, 0.257 \mathrm{~g}$ ) and HMeIm (6 mmol, $0.493 \mathrm{~g}$ ) was prepared by milling the components together for 5 minutes in the presence of $\mathrm{NH}_{4} \mathrm{NO}_{3}(0.08 \mathrm{mmol}$, $6.4 \mathrm{mg}, 4 \mathrm{~mol} \%$ with respect to $\mathrm{CdO}$ ). The resulting mixture was then placed in an incubator at $45{ }^{\circ} \mathrm{C}$ and $100 \% \mathrm{RH}$ for 4 days, after which PXRD indicated complete disappearance of CdO. The product was further analyzed by TGA, FTIR, and ssNMR.

Synthesis of dia-Cd(Im) 2 (2): A 1:2 stoichiometric mixture of $\mathrm{CdO}(0.51 \mathrm{~g})$ and $\mathrm{HIm}(0.55 \mathrm{~g})$ was milled in the presence of $\mathrm{HCafHSO}_{4}$ in a $10 \mathrm{~mL}$ stainless steel milling jar with one $7 \mathrm{~mm}$ diameter (1.3 g weight) stainless steel milling ball for 5 minutes at $30 \mathrm{~Hz}$. The reaction mixture was subsequently aged at $45{ }^{\circ} \mathrm{C}$ and $100 \% \mathrm{RH}$ for 4 days. The resulting offwhite product was washed in $\mathrm{MeOH}$ and dried in vacuo at $80{ }^{\circ} \mathrm{C}$ before analysis.

Synthesis of yqt1-Cd(MeIm) 2 (3): A 1:2 stoichiometric mixture of CdO $(0.51 \mathrm{~g})$ and HMeIm ( $0.66 \mathrm{~g}$ ) were milled in the presence of $\mathrm{HCafHSO}_{4}$ in a $10 \mathrm{~mL}$ stainless steel milling jar with one $7 \mathrm{~mm}$ diameter (1.3 g weight) stainless steel milling ball for 5 minutes at $30 \mathrm{~Hz}$. The reaction mixture was subsequently aged at $45{ }^{\circ} \mathrm{C}$ and $100 \% \mathrm{RH}$ for 2 days. The resulting off-white product was washed in $\mathrm{MeOH}$ and dried in vacuo at $80{ }^{\circ} \mathrm{C}$ before analysis.

Synthesis of $\mathrm{Cd}(\mathrm{HIm})_{6} \cdot 3 \mathrm{H}_{2} \mathrm{O}$ (4): A sample of 2 was aged in $\mathrm{CO}_{2}$ atmosphere at $45^{\circ} \mathrm{C}$ and $100 \% \mathrm{RH}$ for 5 days. The resulting off-white product was washed in $\mathrm{MeOH}$ and dried in vacuo at $80^{\circ} \mathrm{C}$ before analysis.

Mechanochemistry: Following the initial discovery via accelerated aging, 1 was subsequently also synthesized by a targeted exploration of different mechanochemical reaction conditions, eventually finding that it can also be obtained by milling of $\mathrm{Cd}(\mathrm{OH})_{2}$ and HMeIm at elevated temperature $(60$ ${ }^{\circ} \mathrm{C}$ ), using an in-house modified Form-Tech Scientific ball mill. For this purpose, a 1:3 stoichiometric mixture of $\mathrm{Cd}(\mathrm{OH})_{2}(146 \mathrm{mg}, 1 \mathrm{mmol})$ and HMeIm (246 mg, $3 \mathrm{mmol}$ ) was milled in a $15 \mathrm{~mL}$ volume stainless steel milling jar along with two stainless steel balls of $7 \mathrm{~mm}$ diameter $(1.3 \mathrm{~g}$ each) for 90 minutes, at a frequency of $30 \mathrm{~Hz}$ and with jar temperature maintained at $60{ }^{\circ} \mathrm{C}$ using an electronicallycontrolled Peltier-based thermostat. After milling, the product was washed briefly with $10 \mathrm{~mL}$ water on a vacuum funnel. Rietveld analysis indicated the product after washing and evacuation contained small amounts (ca. 3\% by weight) of $\mathrm{Cd}(\mathrm{OH})_{2}$, which was included in the final refinement (Figure 5a).

Powder X-ray Diffraction. PXRD patterns were collected using either a Bruker D2 Phaser benchtop diffractometer or a Bruker D8 Discovery diffractometer. Both diffractometers are equipped with $\mathrm{Cu} K_{\alpha}(\lambda=1.54056 \AA)$ sources operating at a power setting of $30 \mathrm{kV}$ and $10 \mathrm{~mA}$ (D2 Phaser) or $40 \mathrm{kV}$ 
and $40 \mathrm{~mA}$ (D8 Discovery). Powder patterns were collected in the range of $2 \theta=4^{\circ}$ to $40^{\circ}$. Analyses of PXRD patterns were done using DASH 3.3.6, CrystalDiffract 6.7.1, and Panalytical X'Pert HighScore software packages.

Fourier-transform infrared total attenuated reflection (FTIRATR) spectroscopy. FTIR-ATR spectra were collected in the solid state using a Bruker Vertex 70 FTIR-ATR spectrometer in the range of $400 \mathrm{~cm}^{-1}$ to $4000 \mathrm{~cm}^{-1}$. FTIR spectra were analysed using Bruker OPUS software.

Solid-State NMR (SSNMR) spectroscopy. All SSNMR experiments were conducted on a Varian Infinity Plus console with an Oxford 9.4 $\mathrm{T}\left(\mathrm{v}_{0}\left({ }^{1} \mathrm{H}\right)=400 \mathrm{MHz}, v_{0}\left({ }^{111} \mathrm{Cd}\right)=84.86\right.$ $\left.\mathrm{MHz}, v_{0}\left({ }^{13} \mathrm{C}\right)=100.58 \mathrm{MHz}, v_{0}\left({ }^{14} \mathrm{~N}\right)=28.91 \mathrm{MHz}\right)$ wide-bore magnet. Samples were finely ground with a mortar and pestle and packed into either $4 \mathrm{~mm}$ outer diameter (o.d.) zirconia rotors $\left({ }^{1} \mathrm{H},{ }^{13} \mathrm{C},{ }^{111} \mathrm{Cd}\right.$ MAS NMR experiments) or $5 \mathrm{~mm}$ o.d. glass tubes $\left({ }^{14} \mathrm{~N}\right.$ static NMR experiments). Spectra were processed using the NUTS program from Acorn software and analytical simulations were performed using the WSolids $^{50}$ software package. Uncertainties in the ${ }^{111} \mathrm{Cd}$ CS tensor parameters were estimated through bidirectional variation of parameters and visually comparing the resulting simulated and experimental spectra.

${ }^{1} \mathrm{H}$ MAS NMR Experiments were conducted on a Varian/Chemagnetics $4 \mathrm{~mm}$ HX MAS probe. A Bloch decay pulse sequence with calibrated $\pi / 2$ pulse widths of $3.56 \mu \mathrm{s}\left(v_{1}=\right.$ $70 \mathrm{kHz}$ ) was used for all experiments, which were conducted under MAS ( $v_{\text {rot }}=16 \mathrm{kHz}$ ). $4 \mathrm{~K}$ of points were collected with a dwell time of $6.67 \mu$ s (spectral width of 150 $\mathrm{kHz}$ ). The recycle delays were calibrated for each sample to maximize S/N and are shown in Table S1. Peaks were referenced to TMS using adamantane as a secondary reference $\left(\delta_{\text {iso }}=1.87 \mathrm{ppm}\right)$.

${ }^{1} \mathrm{H}^{-13} \mathrm{C} C P / M A S$ NMR. ${ }^{13} \mathrm{C}$ SSNMR experiments were conducted on the same spectrometer and probe using the variable-amplitude cross polarization (VACP) pulse sequence under MAS conditions ${ }^{51}\left(v_{\text {rot }}=10 \mathrm{kHz}\right)$. Optimized contact times and recycle delays are shown in Table S2. The $\pi / 2\left({ }^{1} \mathrm{H}\right)$ pulse width was $7.4 \mu \mathrm{s}$. The spin locking powers were $34 \mathrm{kHz}$ for ${ }^{1} \mathrm{H}$ and $24 \mathrm{kHz}$ for ${ }^{13} \mathrm{C}$. TPPM ${ }^{1} \mathrm{H}$ decoupling was used, with $v_{2}=46 \mathrm{kHz} .8 \mathrm{~K}$ of points were collected with a dwell time of $16.67 \mu$ s (spectral width of $60 \mathrm{kHz}$ ). Peaks were referenced to TMS using adamantane as a secondary reference $\left(\delta_{\text {iso }}=38.57 \mathrm{ppm}\right)$.

${ }^{1} \mathrm{H}^{-111} \mathrm{Cd} C \mathrm{CP} / \mathrm{MAS}$ and CP static NMR. ${ }^{111} \mathrm{Cd}$ SSNMR experiments were conducted using the variable-amplitude cross polarization (VACP) pulse sequence under both MAS ( $v_{\text {rot }}=$ $5 \mathrm{kHz}$ ) and static conditions. Optimized contact times and recycle delays are shown in Table S3. The $\pi / 2\left({ }^{1} \mathrm{H}\right)$ pulse width was $3.5 \mu \mathrm{s}$. The spinning locking powers were $52 \mathrm{kHz}$ for ${ }^{1} \mathrm{H}$ and $42 \mathrm{kHz}$ for ${ }^{111} \mathrm{Cd}$. TPPM ${ }^{1} \mathrm{H}$ decoupling was used, with $v_{2}=58 \mathrm{kHz} .2 \mathrm{~K}$ points were collected with a dwell time of $20 \mu \mathrm{s}$ (spectral width of $50 \mathrm{kHz}$ ). Peaks were referenced to $\mathrm{Cd}\left[\mathrm{ClO}_{4}\right]_{2} \cdot 6 \mathrm{H}_{2} \mathrm{O}$ using $\mathrm{Cd}\left[\mathrm{NO}_{3}\right]_{2} \cdot 4 \mathrm{H}_{2} \mathrm{O}$ as a secondary reference $\left(\delta_{\text {iso }}=-100 \mathrm{ppm}\right)$. While ${ }^{113} \mathrm{Cd}$ (n.a. $=12.22 \%, \gamma=-$ $9.487 \mathrm{MHz} / \mathrm{T}$ ) is usually preferred over ${ }^{111} \mathrm{Cd}$ (n.a. $=12.80$ $\%, \gamma=-9.069 \mathrm{MHz} / \mathrm{T}$ ) for NMR experiments, ${ }^{113} \mathrm{Cd}$ spectra acquired at 9.4 T in Windsor are subject to interfering, semicoherent signals from local FM radio stations. For this reason, ${ }^{111} \mathrm{Cd}$ was chosen as the target nuclide, without incurring any significant losses in signal-to-noise.
${ }^{1} H_{-14} N$ BRAIN-CP/WURST-CPMG. ${ }^{14} \mathrm{~N}$ SSNMR experiments were conducted using the Broadband Adiabatic INversion Cross Polarization pulse sequence coupled with a WURSTCPMG echo train (BRAIN-CP/WURST-CPMG). ${ }^{52-55}$ A $4.9 \mu \mathrm{s}$ $(51 \mathrm{kHz}) \pi / 2$ excitation pulse was used on the ${ }^{1} \mathrm{H}$ channel and $45 \mathrm{kHz}$ of spin-locking power was applied on both channels for the optimized contact time. The WURST spin-locking pulse was swept over $1000 \mathrm{kHz}$ on the ${ }^{14} \mathrm{~N}$ channel. The CPMG refocusing portion of the sequence used $50 \mu \mathrm{s}$ WURST-80 pulses, with $v_{1}=28 \mathrm{kHz}$ and $1000 \mathrm{kHz}$ sweep ranges. The spectral width was $2000 \mathrm{kHz}(0.5 \mu \mathrm{s}$ dwell time). The acquisition period of a single echo was 100 points $(50 \mu \mathrm{s})$. Since the excitation bandwidths associated with the WURST pulses are insufficient to excite the entire breadth of the ${ }^{14} \mathrm{~N}$ powder patterns, the full ${ }^{14} \mathrm{~N}$ NMR spectra were acquired using the frequency-stepped or variable-offset cumulative spectrum (VOCS) technique, ${ }^{56-58}$ where a series of subspectra were acquired with transmitter steps of $100 \mathrm{kHz}$ over the low frequency half of the Pake-like doublet. The subspectra were processed by co-addition of the echoes in the FID into a single echo, application of $20 \mathrm{kHz}$ of Gaussian broadening, Fourier transformation, and subsequent magnitude calculation. The subspectra were then coadded and mirrored about the ${ }^{14} \mathrm{~N}$ Larmor frequency to give the total spectrum. ${ }^{53,59-61}$

Structure Refinement. The PXRD pattern of $\mathbf{1}$ was indexed and the unit cell parameters were determined using the McMaille software package. ${ }^{62}$ The initial structure solution was performed using $\mathrm{DASH}^{63}$ and refined using EXPGUI/GSAS. ${ }^{64,65}$

\section{Results and Discussion}

Brief (five minutes) milling of a solid 1:2 stoichiometric mixture of $\mathrm{CdO}$ and $\mathrm{HMeIm}$ did not induce any reaction, as evidenced by PXRD (Figure S7, ESI). However, PXRD analysis after 12 days at $100 \%$ relative humidity $(\mathrm{RH})$ and $45^{\circ} \mathrm{C}$ revealed partial conversion of $\mathrm{CdO}$ into 1 (Figure 1A). Bragg reflections of $\mathbf{1}$ did not match any cadmium- or other transition metal-based imidazolate structure in the Cambridge Structural Database (CSD). In an attempt to achieve faster, complete conversion into $\mathbf{1}$, aging was repeated in the presence of a catalytic protic salt ( $4 \mathrm{~mol} \%$ with respect to $\mathrm{CdO}$ ) such as $\mathrm{NH}_{4} \mathrm{NO}_{3},\left(\mathrm{NH}_{4}\right)_{2} \mathrm{SO}_{4}$, or caffeinium hydrogensulfate $\left(\mathrm{HCafHSO}_{4}\right)$. The use of these salts to facilitate AA syntheses of MOFs was previously demonstrated, and explained via a proton transfer mechanism involving intermediate imidazolium species. ${ }^{17,66}$ With $\mathrm{NH}_{4} \mathrm{NO}_{3}$, PXRD analysis again revealed the formation of $\mathbf{1}$, with X-ray reflections of residual CdO still observable after 7 days (Figure 1B). However, with $\left(\mathrm{NH}_{4}\right)_{2} \mathrm{SO}_{4}$ and $\mathrm{HCafHSO}_{4}$, the formation of $\mathbf{1}$ was followed by appearance of the known $\mathrm{Cd}(\mathbf{M e I m})_{2}$ framework with a yqt1-topology (CCDC code GUPBOJ) (Figure 1, also S9). After 7 days, both reaction systems quantitatively converted to yqt1-Cd(MeIm) $)_{2}$, as shown by PXRD and thermogravimetric analysis (TGA, Figure S11).

The persistence of $\mathrm{CdO}$ in AA reactions leading to $\mathbf{1}$ suggests that the reactant ratio should be different from the $1: 2$ that was expected for a typical Cd(MeIm) $)_{2}$ framework. Repeating the reaction with $\mathrm{NH}_{4} \mathrm{NO}_{3}$ as the catalytic additive, but using different stoichiometric ratios of reactants revealed that complete conversion of $\mathrm{CdO}$ was achieved with a CdO:HMeIm stoichiometric ratio of 1:3 or higher (Figures 
1C, D). Thermogravimetric analysis of a washed sample in air (Figure S12) indicated that $\mathbf{1}$ consists of $\mathrm{Cd}$ and MeIm species in a 1:3 ratio, suggesting the formula Cd(MeIm) ${ }_{2} \cdot$ HMeIm. Indeed, we subsequently found that the material can also be synthesized mechanochemically, by milling $\mathrm{Cd}(\mathrm{OH})_{2}$ and $\mathrm{HMeIm}$ at an elevated temperature $(60$ ${ }^{\circ} \mathrm{C}$ ) in a 1:3 ratio, which further supports the formula Cd(MeIm) ${ }_{2} \cdot$ HMeIm. The presence of neutral HMeIm in 1 was confirmed by FTIR-ATR, which exhibited absorption bands resembling both solid HMeIm and yqt1-Cd(MeIm) (Figure S15).

As all attempts to obtain single crystals of $\mathbf{1}$ from solution have failed, we targeted structure solution from PXRD data. The unusual 1:3 metal:ligand ratio required us to consider two structural models for 1: (i) an open ZIF consisting of tetrahedral $\mathrm{Cd}^{2+}$ nodes bridged by $\mathbf{M e I m}^{-}$anions, with additional HMeIm included as a guest, or (ii) a ZIF with additional HMeIm coordinated to $\mathrm{Cd}^{2+}$ along with $\mathbf{M e I m}$, leading to a 5- or 6-coordinate $\mathrm{Cd}^{2+}$ environment. To resolve this, we turned to ${ }^{111} \mathrm{Cd}$ SSNMR, as the Cd CS tensor is highly sensitive to the coordination number of the metal and nature of coordinated ligands. ${ }^{67,68}$

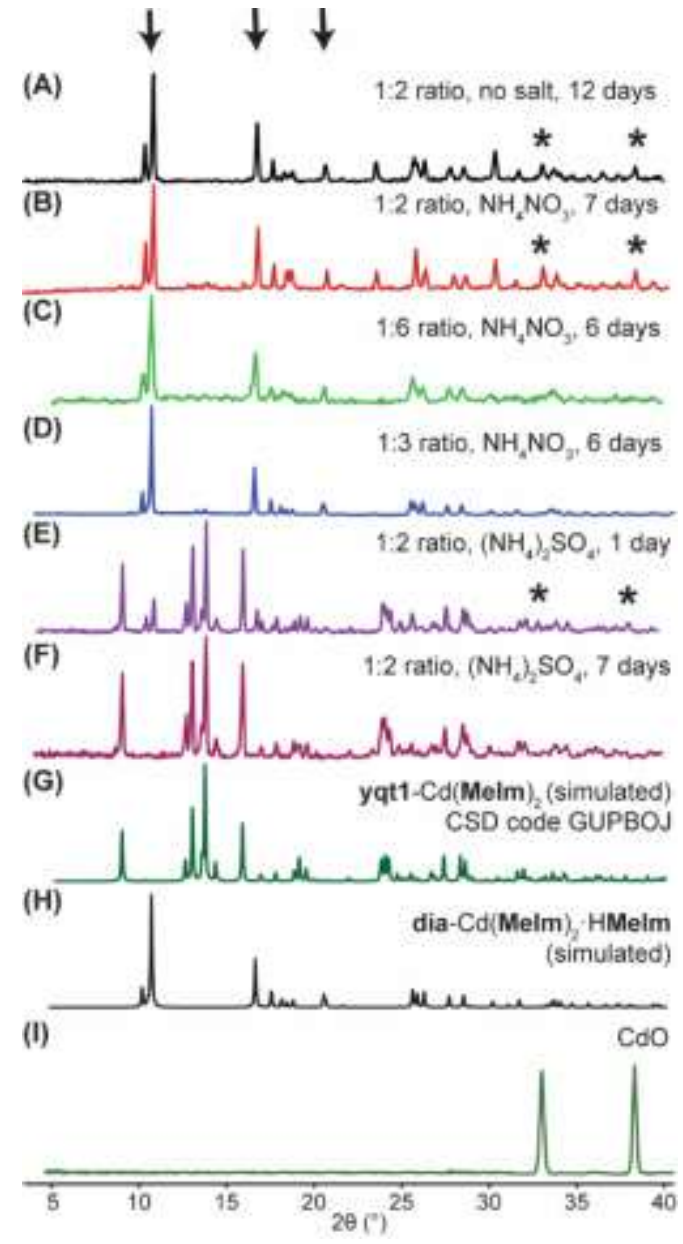

Figure 1. Selected PXRD patterns for AA reactions of $\mathrm{CdO}$ and HMeIm in different ratios: (A) 1:2 ratio, aged for 12 days; (B) 1:2 ratio, aged for 7 day in presence of $\mathrm{NH}_{4} \mathrm{NO}_{3}$; (C) 1:6 ratio, aged in presence of $\mathrm{NH}_{4} \mathrm{NO}_{3}$ for 6 days; (D) 1:3 ratio, aged in presence of $\mathrm{NH}_{4} \mathrm{NO}_{3}$ for 6 days; (E) 1:2 ratio, aged 1 day with $\left(\mathrm{NH}_{4}\right)_{2} \mathrm{SO}_{4}$; (F) 1:2 ratio, aged with $\left(\mathrm{NH}_{4}\right)_{2} \mathrm{SO}_{4}$ for 7 days; $(\mathbf{G})$ simulated pattern for yqt1-Cd(MeIm)2 (CSD code GUPBOJ); (H) simulated pattern for $\mathbf{1}$, and (I) CdO reactant. X-ray reflections corresponding to the dia-phase are indicated with an arrow $(\downarrow)$. Reflections corresponding to unreacted CdO are indicated with an asterisk $(*)$.

In addition to previous reports of the study of MOF materials using ${ }^{113} \mathrm{Cd}$ SSNMR, ${ }^{69,70}$ two studies of systems analogous to those herein have been reported: one on the cadmium analogue of SOD-topology Zn(MeIm) 2 (ZIF-8), consisting of metal nodes tetrahedrally coordinated by $\mathbf{M e I m}^{-},{ }^{71}$ which has a $\delta_{\text {iso }}\left({ }^{113} \mathrm{Cd}\right)=408.3 \mathrm{ppm}$, and one on the discrete complexes $\mathrm{Cd}(\mathrm{HIm})_{6}\left(\mathrm{NO}_{3}\right)_{2}$ and $\mathrm{Cd}(\mathrm{HIm})_{6}(\mathrm{OH}) \mathrm{NO}_{3} \cdot 4 \mathrm{H}_{2} \mathrm{O}$, which feature octahedral $\mathrm{Cd}$ sites with $\delta_{\text {iso }}\left({ }^{113} \mathrm{Cd}\right)=238$ and 272 ppm, respectively. ${ }^{72}$

To gain clear insight into correlations between $\mathrm{Cd}$ coordination environment and CS tensors, we conducted ${ }^{111} \mathrm{Cd}$ SSNMR experiments on selected four- and six-coordinate systems with nitrogen-donor ligands: the imidazolate frameworks dia-Cd(Im) $)_{2}$ (2, CCDC BAYQAU) and yqt1$\mathrm{Cd}(\mathbf{M e I m})_{2}(3),{ }^{46,47}$ both having four-coordinate $\mathrm{Cd}^{2+}$ sites, and the carbonate $\left[\mathrm{Cd}(\mathrm{HIm})_{6}\right]^{2+}\left[\mathrm{CO}_{3}\right]^{2-} \cdot 3 \mathrm{H}_{2} \mathrm{O} \quad(4, \mathrm{CCDC}$ IMCDCP01 $)^{73}$ which has a six-coordinate octahedral $\mathrm{Cd}^{2+}$ site (Figures S16-S18, see Experimental for details on sample preparation).

${ }^{1} \mathrm{H}-{ }^{111} \mathrm{Cd}$ cross-polarization (CP) experiments were conducted under both magic-angle spinning (MAS) and static conditions. MAS experiments allow for the accurate determination of $\delta_{\text {iso }}\left({ }^{111} \mathrm{Cd}\right)$; however, since the Cd CS anisotropies are relatively small, they are challenging to accurately measure from some of the MAS NMR spectra (Figure 2). Hence, static ${ }^{1} \mathrm{H}-{ }^{111} \mathrm{Cd} \mathrm{CP}$ experiments were conducted to obtain spectra that provide Cd CS tensor parameters (Table 1) and further information on the geometries of Cd environments. The ${ }^{111} \mathrm{Cd}$ MAS NMR spectrum of 2 (Figure 2A) reveals $\delta_{\text {iso }}\left({ }^{111} \mathrm{Cd}\right)=436(1) \mathrm{ppm}$ and a clearly resolved nonet coupling pattern corresponding to indirect spin-spin coupling of ${ }^{111} \mathrm{Cd}$ to four ${ }^{14} \mathrm{~N}(\operatorname{spin} I=1)$ nuclei $(2 \mathrm{NI}+1=9$ peaks, intensity ratio: 1:4:10:16:19:16:10:4:1), with ${ }^{1} J\left({ }^{111} \mathrm{Cd},{ }^{14} \mathrm{~N}\right)=140(5) \mathrm{Hz}$. The value of $\delta_{\text {iso }}\left({ }^{111} \mathrm{Cd}\right)$ is consistent with $\delta_{\text {iso }}\left({ }^{113} \mathrm{Cd}\right)$ values reported by Baxter et al., ${ }^{71}$ and Ellis et al. $^{74}$ for four-coordinate $\mathrm{Cd}^{2+}$ with different geometries and mixed ligand types (Figure S3). The Cd environment in $\mathbf{2}$ is non-tetrahedral, as indicated by the large span $(\Omega=225 \mathrm{ppm})$.

The MAS spectrum of $\mathbf{3}$ (Figure 2B) is more complex and appears to consist of two patterns arising from magnetically distinct ${ }^{111} \mathrm{Cd}$ nuclei, with $\delta_{\text {iso }}\left({ }^{111} \mathrm{Cd}\right)$ of 437 and $417 \mathrm{ppm}$, both consistent with four-coordinate $\mathrm{CdN}_{4}$ environments. The signal at $437 \mathrm{ppm}$ has a resolved nonet pattern $\left({ }^{1} J\left({ }^{111} \mathrm{Cd},{ }^{14} \mathrm{~N}\right)=125(5) \mathrm{Hz}\right)$, and is much more intense than the peak at $417 \mathrm{ppm}$, which lacks resolvable fine structure. However, the static spectrum of $\mathbf{3}$ reveals three overlapping patterns of magnetically distinct $\mathrm{Cd}$ sites, two of which have virtually identical $\delta_{\text {iso }}\left({ }^{111} \mathrm{Cd}\right)$ of $437 \mathrm{ppm}$ (sites I and III, Table 1), but disparate CS tensor parameters; this almost certainly accounts for the broadening and increased intensity of the signal at $437 \mathrm{ppm}$ in the MAS spectra, representing a rare case where distinct patterns are more easily resolved using static SSNMR.

Table 1. Experimentally determined cadmium chemical shift tensor parameters. 


\begin{tabular}{lllcccccc}
\hline Compound & Formula & Site & $\begin{array}{c}\delta_{\text {iso }}{ }^{a} \\
(\mathrm{ppm})\end{array}$ & $\begin{array}{c}\Omega^{b} \\
(\mathrm{ppm})\end{array}$ & $\kappa^{c}$ & $\begin{array}{r}\delta_{11^{d}} \\
(\mathrm{ppm})\end{array}$ & $\begin{array}{c}\delta_{22}{ }^{d} \\
(\mathrm{ppm})\end{array}$ & $\begin{array}{c}\delta_{33^{d}} \\
(\mathrm{ppm})\end{array}$ \\
\hline $\mathbf{1}$ & dia-Cd(MeIm) $2 \cdot$ HMeIm & - & $441(1)$ & $40(3)$ & $0.0(2)$ & $461(2)$ & $441(3)$ & $421(2)$ \\
$\mathbf{2}$ & dia-Cd(Im) 2 & - & $436(2)$ & $225(5)$ & $-0.19(2)$ & $556(3)$ & $422(3)$ & $331(3)$ \\
$\mathbf{3}$ & yqt1-Cd(MeIm) 2 & I & $437(1)$ & $85(5)$ & $-0.68(2)$ & $489(3)$ & $418(2)$ & $404(2)$ \\
& & II & $417(3)$ & $280(5)$ & $-0.51(2)$ & $589(4)$ & $354(4)$ & $308(4)$ \\
& & III & $437(1)$ & $200(5)$ & $-0.40(2)$ & $550(3)$ & $410(20$ & $350(2)$ \\
$\mathbf{4}$ & {$\left[\mathrm{Cd}(\mathbf{H I m})_{6}\right]^{2+}\left[\mathrm{CO}_{3}\right]^{2-}$} & - & $251(2)$ & $42(2)$ & $0.55(2)$ & $268(2)$ & $259(2)$ & $226(2)$ \\
\hline
\end{tabular}

$a$ Isotropic shift: $\delta_{\text {iso }}=\left(\delta_{11}+\delta_{22}+\delta_{33}\right) / 3 ;{ }^{b}$ Span: $\Omega=\delta_{11}-\delta_{33} ;{ }^{c}$ Skew: $\kappa=3\left(\delta_{22}-\delta_{\text {iso }}\right) / \Omega$.

${ }^{d}$ The principal components of the chemical shift tensor are defined as $\delta_{11} \geq \delta_{22} \geq \delta_{33}$. While the MAS spectra are useful for determining the values of $\delta$ iso $\left({ }^{111} \mathrm{Cd}\right)$, the full sets of tensor parameters are determined more accurately from the static spectra (see text for details). Experimental uncertainties in the last digit(s) for each parameter are indicated in parentheses and were estimated using bidirectional variation of the Herzfeld-Berger convention parameters (i.e., $\delta_{\text {iso, }} \Omega$, and $\kappa$ ) in the simulation software. The uncertainties in the principal components were calculated using the rules for the propagation of uncertainties.

(A)

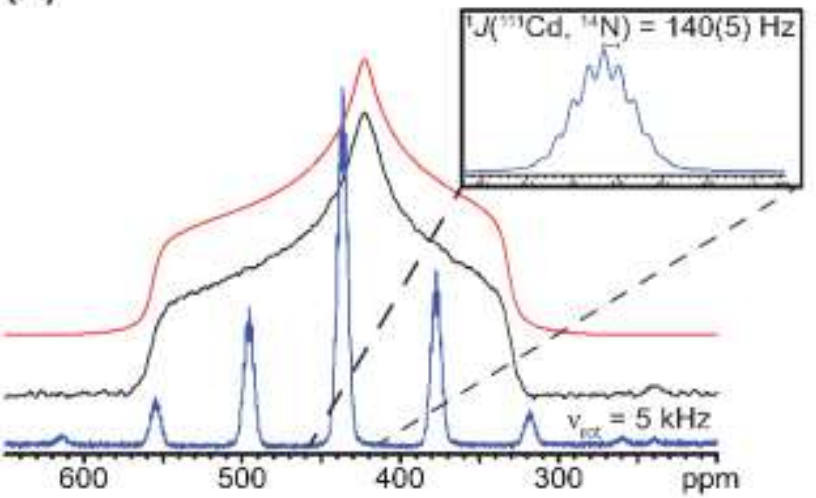

(B)

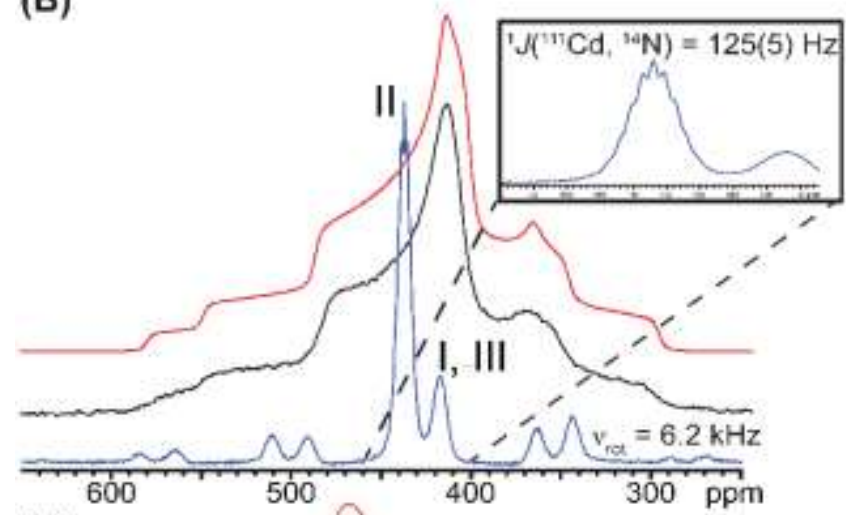

(C)

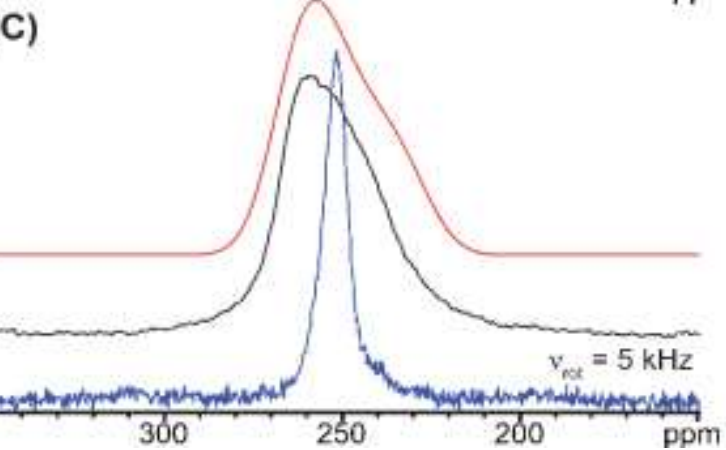

Figure 2. Experimental ${ }^{1} \mathrm{H}-111 \mathrm{Cd} \mathrm{CP}$ NMR spectra acquired under MAS (blue) and static (black) conditions, with simulations of the static spectra (red) for (A) 2, (B) 3, and (C) 4. The signals corresponding to the different Cd environments in $\mathbf{3}$ are indicated in the figure with site labels (I, II, and III).

These observations are consistent with the structure of $\mathbf{3}$, which has two distinct $\mathrm{Cd}^{2+}$ environments, one of which has a disordered MeIm- ligand and a distorted tetrahedral geometry. Hence, the two patterns with large spans $(\Omega=200$ ppm and $280 \mathrm{ppm}$ ) correspond to $\mathrm{Cd}^{2+}$ sites with two possible ligand orientations. The pattern with $\Omega=85 \mathrm{ppm}$ (site II, Table 1) corresponds to the $\mathrm{Cd}^{2+}$ site with a less distorted tetrahedral environment and minimal disorder. A deconvolution of the static spectrum is given in Figure S4.

The ${ }^{111} \mathrm{Cd}$ MAS spectrum of 4 (Figure 2C) has a single broad peak with $\delta_{\text {iso }}\left({ }^{111} \mathrm{Cd}\right)=251 \mathrm{ppm}$, consistent with a six-coordinate $\mathrm{CdN}_{6}$ environment. While a smaller span is indicative of near-octahedral symmetry, the expected coupling pattern (13 signals due to coupling to six ${ }^{14} \mathrm{~N}$ nuclei, $2 N I+1=13$ peaks, intensity ratio: $1: 6: 21: 50: 90: 126: 141: 126: 90$ : 50:21:6:1) is not seen, potentially due to a distribution of ${ }^{1} J\left({ }^{14} \mathrm{~N},{ }^{111} \mathrm{Cd}\right)$ coupling constants and/or efficient transverse relaxation $\left(T_{2}\right)$ of ${ }^{111} \mathrm{Cd}$ caused by scalar relaxation of the second kind. ${ }^{75}$

The information on Cd CS tensors for 2-4 (Table 1) and corresponding data from the literature enabled the identification of the appropriate structural model for $\mathbf{1}$. The ${ }^{111} \mathrm{Cd}$ MAS NMR spectrum of $\mathbf{1}$ (Figure $\mathbf{3 A}$ ) reveals only one signal $\left(\delta_{\text {iso }}\left({ }^{111} \mathrm{Cd}\right)=441 \mathrm{ppm}\right)$, consistent with one crystallographically unique $\mathrm{Cd}^{2+}$ site in a four-coordinate environment. This suggests that $\mathbf{1}$ is a $\mathrm{Cd}(\mathbf{M e I m})_{2}$ framework with included HMeIm guests. The broad MAS spectrum with no resolved J-couplings is indicative of disorder, further substantiated by the ${ }^{111} \mathrm{Cd}$ static CP spectrum and simulation (Figures $3 \mathbf{B}, \mathbf{C}$ ), which do not show any clear discontinuities. The disorder may be caused by HMeIm guests within the MOF pores assuming random orientations; hence, further multinuclear SSNMR experiments were done to confirm HMeIm inclusion in the pores. 


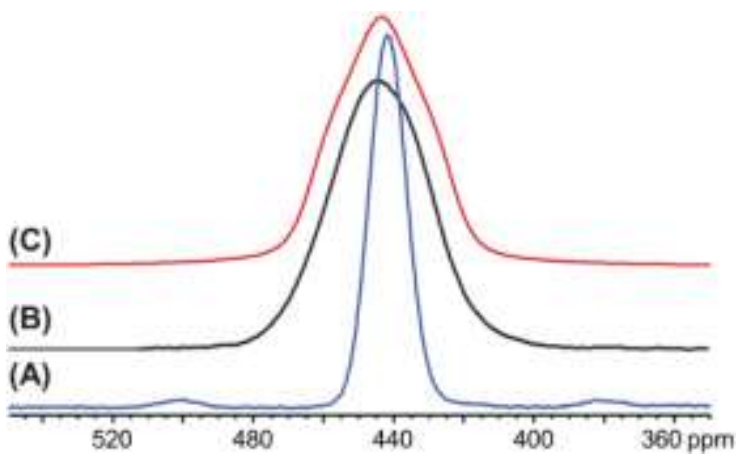

Figure 3. Experimental ${ }^{1} \mathrm{H}-111 \mathrm{Cd}$ CP NMR spectra under (A) MAS ( $\mathrm{V}_{\text {rot }}=5 \mathrm{kHz}$ ) and (B) static conditions for compound $\mathbf{1}$, with an accompanying simulation of the static spectrum in (C).

The ${ }^{1} \mathrm{H}-{ }^{13} \mathrm{C}$ CP/MAS spectrum of bulk HMeIm exhibits four signals (Figure 4A), corresponding to the four distinct carbon environments. The corresponding spectrum of $\mathbf{1}$ has many signals matching those of bulk HMeIm, suggesting the presence of unbound HMeIm in 1. This is supported by the ${ }^{1} \mathrm{H}$ MAS NMR spectrum of 1 (Figure 4B), which displays a signal at $c a .13 .3 \mathrm{ppm}$, consistent with the $\mathrm{N}-\mathrm{H}$ proton of neutral HMeIm. The presence of unbound HMeIm was also confirmed using ${ }^{1} \mathrm{H}^{-14} \mathrm{~N}$ BRAIN-CP NMR experiments (Figures S5-S6).

(A)

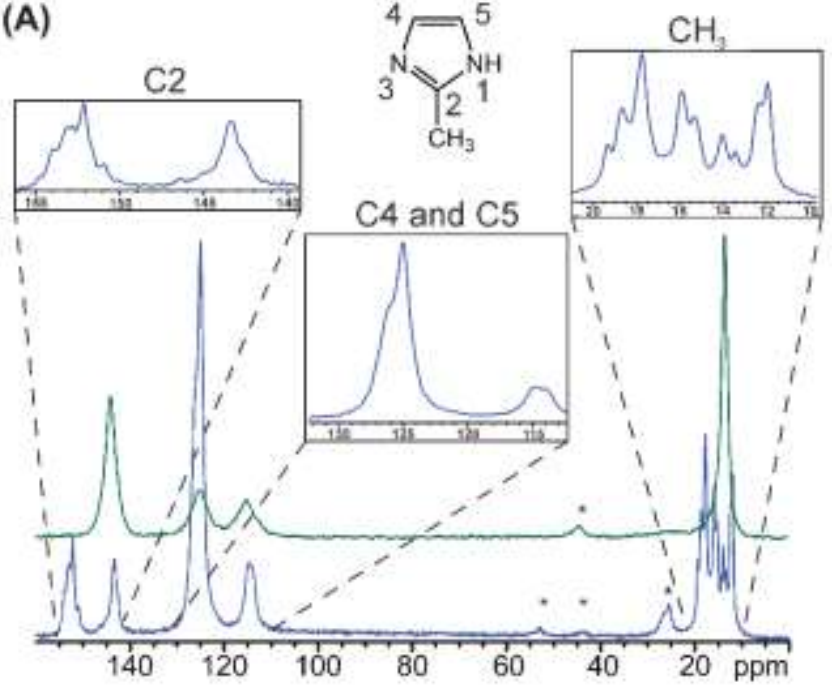

(B)

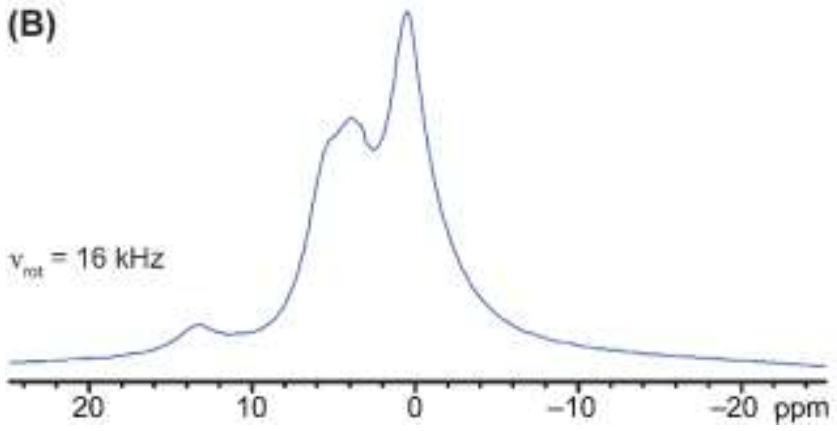

Figure 4. (A) ${ }^{1} \mathrm{H}-{ }^{13} \mathrm{C} \mathrm{CP} / \mathrm{MAS}\left(v_{\text {rot }}=10 \mathrm{kHz}\right.$ ) spectra of bulk HMeIm (green) and $\mathbf{1}$ (blue), along with the numbering scheme for the imidazole ring atoms. Chemical shift ranges corresponding to the different carbon environments in the MeIm rings are shown in the insets, and spinning sidebands are indicated with the ${ }^{\prime * '}$ symbol. (B) ${ }^{1} \mathrm{H}$ MAS spectrum of $\mathbf{1}\left(v_{\text {rot }}=16 \mathrm{kHz}\right)$.
The extensive framework- and guest-related information provided by SSNMR enabled the choice of a suitable model for structural characterization of $\mathbf{1}$ from PXRD data. Indexing the PXRD pattern of $\mathbf{1}$ using McMaille ${ }^{62}$ revealed an orthorhombic unit cell with $a=10.0807(2) \AA, b=$ $16.7415(3) \AA$, and $c=9.4264(1) \AA$. Intensity statistics and cell volume considerations suggested Ima2 as the most likely space group. While structure solution by $\mathrm{DASH}^{63}$ produced a model with symmetry-imposed disorder, we also repeated the structure determination using space group Pna $2_{1}$, which is the maximal subgroup of Ima2 that allows the ligands to reside in general positions. This led to a slightly better fit of the structure to the experimental data. Even though the lower-symmetry model appears more likely, it is important to note that some degree of disorder in the orientation of the coordinated imidazole rings cannot be excluded. The crystal structure after successful refinement with EXPGUI/GSAS ${ }^{64,65}$ revealed a distorted diamondoid (dia) topology $\mathrm{Cd}(\mathbf{M e I m})_{2}$ network (Figure 5a,b).

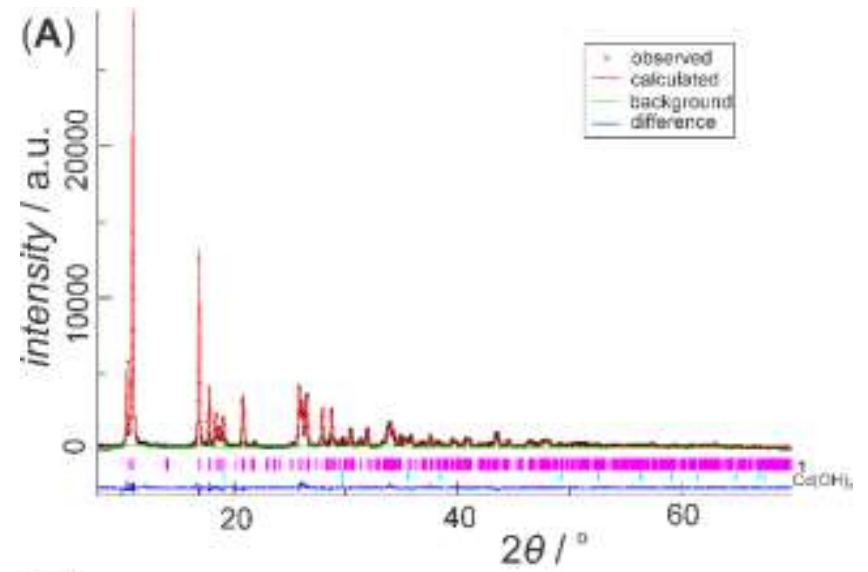

(B)

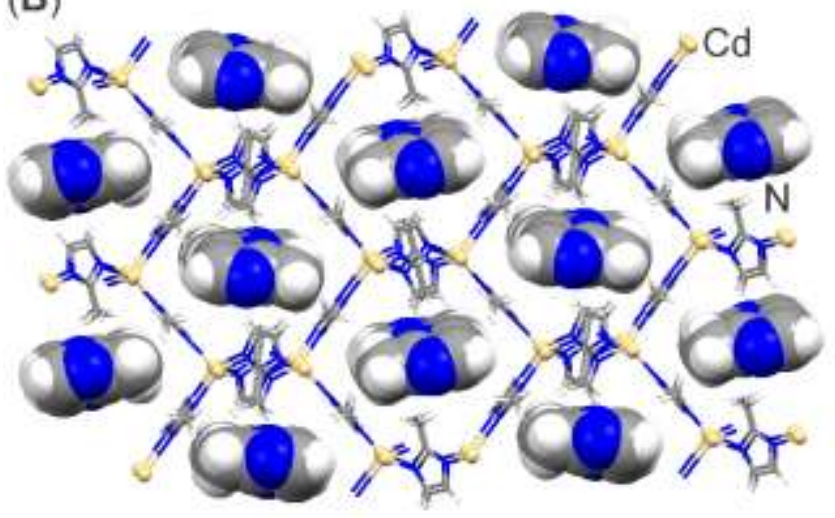

(C)

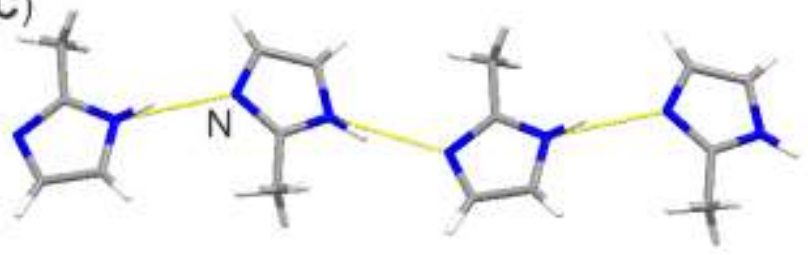

Figure 5. (A) Final Rietveld fit and (B) fragment of the crystal structure of dia-Cd(MeIm) $)_{2} \cdot$ HMeIm (1), viewed down the crystallographic $c$-axis. (C) Fragment of a single hydrogenbonded chain of HMeIm guests in a channel of $\mathbf{1}$, propagating along the crystallographic $c$-axis. 
The dia-Cd(MeIm) $)_{2}$ framework exhibits channels parallel to the crystallographic $c$-axis, that are populated by HMeIm molecules arranged into one-dimensional channels through short $\mathrm{N} \cdots \mathrm{N}$ contacts of $2.67 \AA$, which is indicative of polymerization through $\mathrm{N}-\mathrm{H} \cdots \mathrm{N}$ hydrogen bonds (Figure 5c). The structure of the hydrogen-bonded chains resembles that found in crystalline solid HMeIm, with antiparallel orientation of 2-methyl substituents on neighboring molecules, and a short $\mathrm{H}-\mathrm{H} \cdots \mathrm{N}$ hydrogen bond $(\mathrm{N} \cdots \mathrm{N}$ distance of ca. $2.82 \AA$ ). ${ }^{76}$ The role of HMeIm guest in the formation and retention of the dia-Cd(MeIm) $)_{2} \cdot \mathrm{HMeIm}$ structure was further explored by conducting an AA reaction of $\mathrm{CdO}$ and HMeIm in a 1:3 stoichiometric ratio in the presence of $\left(\mathrm{NH}_{4}\right)_{2} \mathrm{SO}_{4}$ at $45{ }^{\circ} \mathrm{C}$ and $100 \% \mathrm{RH}$. This reaction led to quantitative formation of $\mathbf{1}$ (Figure S9), revealing that the formation of the open dia-framework is induced and stabilized by excess HMeIm, independent of the salt additive used in the reaction. While dia-Cd(MeIm) $)_{2} \cdot \mathrm{HMeIm}$ was stable upon storage for months, heating dia$\mathrm{Cd}(\mathrm{MeIm})_{2} \cdot \mathrm{HMeIm}$ to $200{ }^{\circ} \mathrm{C}$ was found to lead to loss of HMeIm guest by sublimation, yielding yqt1-Cd(MeIm)2.

\section{Conclusions}

In summary, we have shown how solvent-free accelerated aging, coupled with NMR-enhanced crystallography, can allow for the discovery, structural characterization, and development of a route to synthesize a novel open MOF. The discovery of a new material in a well-studied system such as $\mathrm{Cd}(\mathbf{M e I m})_{2}{ }^{46,47}$ highlights the important role that reactivity under solvent-free, mild conditions can play in establishing phase landscapes of MOFs, while at the same time providing the first example of a new, structurally characterized MOF obtained by accelerated aging. Importantly, while the new dia-topology phase was discovered using accelerated aging, recognizing its existence enabled us to conduct a subsequent targeted synthesis of the same material using mechanochemistry. Whereas solid-state NMR spectroscopy has been used to direct structural characterization of substances, typically by indicating the content of asymmetric unit $\left(Z^{\prime}\right)$, the work herein highlights a more active role of solid-state NMR in driving structural characterization of the herein discovered new member of the $\mathrm{Cd}(\mathbf{M e I m})_{2}$ framework family, based on direct spectroscopic elucidation of the coordination geometry around the framework nodes.

\section{ASSOCIATED CONTENT}

Supporting Information. Selected SSNMR, PXRD, FTIR-ATR and TGA data, illustrations of the cadmium coordination environments in model systems $\mathbf{2 - 4}$, as well as crystallographic infromation for $\mathbf{1}$ in CIF format. The CIF file for $\mathbf{1}$ has also been deposited with the Cambridge Crystallographic Data Centre CCDC, deposition code 1987190. This material is available free of charge via the Internet at http://pubs.acs.org.

\section{AUTHOR INFORMATION}

\section{Corresponding Author}

* Robert W. Schurko, Department of Chemistry and Biochemistry, Florida State University, Tallahassee, FL, 32308. E-mail: rschurko@fsu.edu

* Tomislav Friščić, bDepartment of Chemistry, McGill University, Montreal, QC, Canada, H3A 0B8. E-mail:

tomislav.friscic@mcgill.ca

\section{Present Addresses}

$\dagger$ Department of Chemistry, University of Cambridge, Cambridge, UK, CB2 $1 \mathrm{EW}$.

\section{Author Contributions}

The manuscript was written through contributions of all authors. All authors have given approval to the final version of the manuscript.

\section{Funding Sources}

Natural Science and Engineering Research Council (NSERC) Research Tools and Instrument (RTI) grant, NSERC Discovery Grants (NSERC RGPIN-2016_06642, RGPIN-2017-06467,) and E. W. R. Steacie Memorial Fellowship (SMFSU 507347-17). Canadian Foundation for Innovation (CFI)

Ontario Innovation Trust (OIT)

University of Windsor

The Florida State University

The National High Magnetic Field Laboratory (NHMFL), which is funded by the National Science Foundation Cooperative Agreement (DMR-1644779) and by the State of Florida

\section{Notes}

Any additional relevant notes should be placed here.

\section{ACKNOWLEDGMENT}

R.W.S. and T.F. acknowledge the support of the Natural Science and Engineering Research Council (NSERC, Canada) through Research Tools and Instrument (RTI) grant, NSERC Discovery Grant (NSERC RGPIN-2016_06642, RGPIN-2017-06467,) and E. W. R. Steacie Memorial Fellowship (SMFSU 507347-17). The authors are grateful to the Canadian Foundation for Innovation (CFI), the Ontario Innovation Trust (OIT) and the University of Windsor for support of solid-state characterization facilities. R.W.S. is grateful for research support from The Florida State University and the National High Magnetic Field Laboratory (NHMFL), which is funded by the National Science Foundation Cooperative Agreement (DMR-1644779) and by the State of Florida.

\section{ABBREVIATIONS}

HMeIm, 2-methylimidazole; HIm, imidazole; SSNMR, solidstate nuclear magnetic resonance; PXRD. powder X-ray diffraction; TGA, thermogravimetric analysis; FTIR-ATR, Fouriertransform infrared attenuated total reflectance.

\section{REFERENCES}

1. Furukawa, H.; Cordova, K. E.; O'Keeffe, M.; Yaghi, O. M. The Chemistry and applications of metal-organic frameworks. Science $\mathbf{2 0 1 3}$, $341,974$.

2 Rungtaweevoranit, B.; Diercks, C. S.; Kalmutzki, M. J.; Yaghi, O. M. Spiers Memorial Lecture: Progress and prospects of reticular chemistry. Faraday Discuss. 2017, 201, 9-45.

3 Li, J.-R.; Kuppler, R. J.; Zhou, H.-C. Selective gas adsorption and separation in metal-organic frameworks. Chem. Soc. Rev. 2009, 38, 1477-1504.

4 Li, J. R.; Ma, Y.; McCarthy, M. C.; Sculley, J.; Yu, J.; Jeong, H. K.; Balbuena, P. B.; Zhou, H. C. Carbon dioxide capture-related gas adsorption and separation in metal-organic frameworks. Coord. Chem. Rev. 2011, 255, 1791-1823.

5 Bloch, E. D.; Queen, W. L.; Krishna, R.; Zadrozny, J. M.; Brown, C. M.; Long, J. R. Hydrocarbon separations in a metal-organic framework with open iron(II) coordination sites. Science 2012, 335, 1606-1610. 
6 Bae, Y.-S.; Lee, C. Y.; Kim, K. C.; Farha, O. K.; Nickias, P.; Hupp, J. T.; Nguyen, S. T.; Snurr, R. Q. High propene/propane selectivity in isostructural metal-organic frameworks with high densities of open metal sites. Angew. Chem. Int. Ed. 2012, 51, 1857-1860.

7 Ma, L.; Abney, C.; Lin, W. Enantioselective catalysis with homochiral metal-organic frameworks. Chem. Soc. Rev. 2009, 38, 12481256.

8 Liu, J.; Chen, L.; Cui, H.; Zhang, J.; Zhang, L.; Su, C.-Y. Applications of metal-organic frameworks in heterogeneous supramolecular catalysis. Chem. Soc. Rev. 2014, 43, 6011-6061.

9 de Lange, M. F.; Verouden, K. J. F. M.; Vlugt, T. J. H.; Gascon, J.; Kapteijn, F. Adsorption-driven heat pumps: the potential of metalorganic frameworks. Chem. Rev. 2015, 115, 12205-12250.

10. Frameworks for commercial success. Nat. Chem. 2016, 8, 987. 11. Mueller, U.; Schubert, M.; Teich, F.; Puetter, H.; Pastre, J. Metalorganic frameworks - prospective industrial applications. J. Mater. Chem. 2006, 16, 626-636.

12. Czaja, A. U.; Trukhan, N.; Müller, U. Industrial applications of metal-organic frameworks. Chem. Soc. Rev. 2009, 38, 1284-1293.

13. Desantis, D.; Mason, J. A.; James, B. D.; Houchins, C.; Long, J. R.; Veenstra, M. Techno-economic analysis of metal-organic frameworks for hydrogen and natural gas storage. Energy \& Fuels 2017, 31, 2024-2032.

14. Julien, P. A.; Mottillo, C.; Friščić, T. Metal-organic frameworks meet scalable and sustainable synthesis. Green Chem. 2017, 19, 2729-2747.

15. Akimbekov, Z.; Katsenis, A. D.; Nagabhushana, G. P.; Ayoub, G.; Arhangelskis, M.; Morris, A. J.; Friščić, T.; Navrotsky, A. Experimental and theoretical evaluation of the stability of true MOF polymorphs explains their mechanochemical interconversions. J. Am Chem. Soc. 2017, 139, 7952-7957.

16. Katsenis, A. D.; Puškarić, A.; Štrukil, V.; Mottillo, C.; Julien, P. A.; Užarević, K.; Pham, M.-H.; Do, T.-O.; Kimber, S. A. J.; Lazić, P.; Magdysyuk, 0.; Dinnebier, R. E.; Halasz, I.; Friščić, T. In situ X-ray diffraction monitoring of a mechanochemical reaction reveals a unique topology metal-organic framework. Nat. Commun. 2015, 6:6662.

17. Cliffe, M. J.; Mottillo, C.; Stein, R. S.; Bučar, D.-K.; Friščić, T. Accelerated aging: a low energy, solvent-free alternative to solvothermal and mechanochemical synthesis of metal-organic materials. Chem. Sci. 2012, 3, 2495-2500.

18. Zhang, J. P.; Zhang, Y. B.; Lin, J. Bin; Chen, X. M. Metal azolate frameworks: from crystal engineering to functional materials. Chem. Rev. 2012, 112, 1001-1033.

19. Park, K. S.; Zheng, N.; Côté, A. P.; Choi, J. Y.; Huang, R.; UribeRomo, F. J.; Chae, H. K.; O'Keeffe, M.; Yaghi, O. M. Exceptional chemical and thermal stability of zeolitic imidazolate frameworks. Proc. Natl. Acad. Sci. U. S. A. 2006, 103, 10186-10191.

20 Mottillo, C.; Lu, Y.; Pham, M.-H.; Cliffe, M. J.; Do, T.-O.; Friščić, T. Mineral neogenesis as an inspiration for mild, solvent-free synthesis of bulk microporous metal-organic frameworks from metal (Zn, Co) oxides. Green Chem. 2013, 15, 2121-2131.

21. Užarević, K.; Wang, T. C.; Moon, S.-Y.; Fidelli, A. M.; Hupp, J. T.; Farha, O. K.; Friščić, T. Mechanochemical and solvent-free assembly of zirconium-based metal-organic frameworks. Chem. Comm. 2016, 52, 2133-2136.

22. Ashbrook, S. E.; Dawson, D. M. Exploiting periodic first-principles calculations in NMR spectroscopy of disordered solids. Acc. Chem. Res. 2013, 46, 1964-1974.

23. Massiot, D.; Messinger, R. J.; Cadars, S.; Deschamps, M.; Montouillout, V.; Pellerin, N.; Veron, E.; Allix, M.; Florian, P.; Fayon, F. Topological, geometric, and chemical order in materials: Insights from solid-state NMR. Acc. Chem. Res. 2013, 46, 1975-1984.

24. Moran, R. F.; Dawson, D. M.; Ashbrook, S. E. Exploiting NMR spectroscopy for the study of disorder in solids. Int. Rev. Phys. Chem. 2017, 36, 39-115.

25. Bryce, D. L. NMR crystallography: structure and properties of materials from solid-state nuclear magnetic resonance observables. IUCrJ 2017, 4, 350-359.
26. Ashbrook, S. E.; McKay, D. Combining solid-state NMR spectroscopy with first-principles calculations - a guide to NMR crystallography. Chem. Comm. 2016, 52, 7186-7204.

27. Sutrisno, A.; Huang, Y. Solid-state NMR: a powerful tool for characterization of metal-organic frameworks. Solid State Nucl. Magn. Reson. 2013, 49, 1-11.

28. Hoffmann, H. C.; Debowski, M.; Müller, P.; Paasch, S.; Senkovska, I.; Kaskel, S.; Brunner, E. Solid-state NMR spectroscopy of metalorganic framework compounds (MOFs). Materials, 2012, 5, 25372572

29. He, P.; Lucier, B. E. G.; Terskikh, V. V.; Shi, Q.; Dong, J.; Chu, Y.; Zheng, A.; Sutrisno, A.; Huang, Y. Spies within metal-organic frameworks: investigating metal centers using solid-state NMR. J. Phys. Chem. C 2014, 118, 23728-23744.

30. Baias, M.; Lesage, A.; Aguado, S.; Canivet, J.; Moizan-Basle, V.; Audebrand, N.; Farrusseng, D.; Emsley, L. Superstructure of a substituted zeolitic imidazolate metal-organic framework determined by combining proton solid-state NMR spectroscopy and DFT calculations. Angew. Chem. Int. Ed. 2015, 54, 5971-5976.

31. Chen, S.; Lucier, B. E. G.; Chen, M.; Terskikh, V. V; Huang, Y. Probing calcium-based metal-organic frameworks via natural abundance ${ }^{43}$ Ca solid-state NMR spectroscopy. Chem. Eur. J. 2018, 24 , 8732-8736.

32. Rossini, A. J.; Zagdoun, A.; Lelli, M.; Canivet, J.; Aguado, S.; Ouari, O.; Tordo, P.; Rosay, M.; Maas, W. E.; Copéret, C.; Farrusseng, D.; Emsley, L.; Lesage, A. Dynamic nuclear polarization enhanced solid-state NMR spectroscopy of functionalized metal-organic frameworks. Angew. Chem. Int. Ed. 2012, 51, 123-127.

33. Habib, H. A.; Hoffmann, A.; Höppe, H. A.; Steinfeld, G.; Janiak, C. Crystal structure solid-state cross polarization magic angle spinning ${ }^{13} \mathrm{C}$ NMR correlation in luminescent $\mathrm{d}^{10}$ metal-organic frameworks constructed with the 1,2-bis(1,2,4-triazol-4-yl)ethane ligand. Inorg. Chem. 2009, 48, 2166-2180.

34. Devautour-Vinot, S.; Maurin, G.; Serre, C.; Horcajada, P.; Paula Da Cunha, D.; Guillerm, V.; De Souza Costa, E.; Taulelle, F.; Martineau, C. Structure and dynamics of the functionalized MOF type UiO-66(Zr): NMR and dielectric relaxation spectroscopies coupled with DFT calculations. Chem. Mater. 2012, 24, 2168-2177.

35. Kolokolov, D. I.; Jobic, H.; Stepanov, A. G.; Guillerm, V.; Devic, T.; Serre, C.; Férey, G. Dynamics of benzene rings in MIL-53(Cr) and MIL-47(V) frameworks Studied by ${ }^{2} \mathrm{H}$ NMR spectroscopy. Angew. Chem. Int. Ed. 2010, 49, 4791-4794.

36. Kong, X.; Deng, H.; Yan, F.; Kim, J.; Swisher, J. A.; Smit, B.; Yaghi, O. M.; Reimer, J. A. Mapping of functional groups in metal-organic frameworks. Science 2013, 341, 882-885.

37. Fu, Y.; Kang, Z.; Yin, J.; Cao, W.; Tu, Y.; Qang, Q.; Kong, X. Duet of acetate and water at the defects of metal-organic frameworks. Nano Lett. 2019, 19, 1618-1624.

38. Madsen, R. S. K.; Qiao, A.; Sen, J.; Hung, I.; Chen, K.; Gan, Z.; Sen, S.; Yue, Y. Ultrahigh-field $67 \mathrm{Zn}$ NMR reveals short-range disorder in zeolitic imidazolate framework glasses. Science 2020, 367, 14731476

39. Taulelle, F.; Bouchevreau, B.; Martineau, C. NMR crystallography driven structure determination: nanoporous materials. CrystEngComm 2013, 15, 8613-8622.

40. Kobera, L.; Rohlicek, J.; Czernek, J.; Abbrent, S.; Streckova, M.; Sopcak, T.; Brus, J. Unexpected crystallization patterns of zinc boron imidazolate framework ZBIF-1: NMR crystallography of integrated metal-organic frameworks. ChemPhysChem 2017, 18, 3576-3582.

41. Etter, M. C.; Vojta, G. M. The use of solid-state NMR and X-ray crystallography as complementary tools for studying molecular recognition. J. Mol. Graph. 1989, 7, 3-11.

42. Enright, G. D.; Terskikh, V. V.; Brouwer, D. H.; Ripmeester, J. A. The structure of two anhydrous polymorphs of caffeine from single-crystal diffraction and ultrahigh-field solid-state ${ }^{13} \mathrm{C}$ NMR spectroscopy. Cryst. Growth Des. 2007, 7, 1406-1410.

43. Vogt, F. G.; Katrincic, L. M.; Long, S. T.; Mueller, R. L.; Carlton, R. A.; Sun, Y. T.; Johnson, M. N.; Copley, R. C. B.; Light, M. E. 
Enantiotropically-related polymorphs of \{4-(4-chloro-3-fluorophenyl)-2-[4-(methyloxy)phenyl]-1,3-thiazol-5-yl $\}$ acetic acid: Crystal structures and multinuclear solid-state NMR. J. Pharm. Sci. 2008, 97, 4756-4782.

44. Steed, K. M.; Steed, J. W. Packing problems: High Z' crystal structures and their relationship to cocrystals, inclusion compounds, and polymorphism. Chem. Rev. 2015, 115, 2895-2933.

45. Xu, Y.; Southern, S. A.; Szell, P. M. J.; Bryce, D. L. The role of solidstate nuclear magnetic resonance in crystal engineering. CrystEngComm 2016, 18, 5236-5252.

46. Tian, Y.-Q.; Yao, S.-Y.; Gu, D.; Cui, K.-H.; Guo, D.-W.; Zhang, G.; Chen, Z.-X.; Zhao, D.-Y. Cadmium imidazolate frameworks with polymorphism, high thermal stability, and a large surface area. Chem. Eur. J. 2010, 16, 1137-1141.

47. Yao, S.-Y.; Tian, Y.-Q. An exceptional self-penetrating 4-connected network derived from a $(3,4)$-connected net of tfa-c topology. CrystEngComm 2010, 12, 697-699.

48. Karagiaridi, O.; Bury, W.; Sarjeant, A. A.; Stern, C. L.; Farha, O. K.; Hupp, J. T. Synthesis and characterization of isostructural cadmium zeolitic imidazolate frameworks via solvent-assisted linker exchange. Chem. Sci. 2012, 3, 3256-3260.

49. Fujii, K.; Garay, A. L.; Hill, J.; Sbircea, E.; Pan, Z.; Xu, M.; Apperley, D. C.; James, S. L.; Harris, K. D. M. Direct structure elucidation by powder X-ray diffraction of a metal-organic framework material prepared by solvent-free grinding. Chem. Comm. 2010, 46, 75727574.

50. WSolids Software Package, Eichele, K.; Wasylishen, R. E., 2001. 51. Peersen, O. B.; Wu, X.; Kustanovich, I.; Smith, S. O. Variable-amplitude cross-polarization MAS NMR. J. Magn. Reson. Ser. A 1993 , 104, 334-339.

52. Harris, K. J.; Lupulescu, A.; Lucier, B. E. G.; Frydman, L.; Schurko, R. W. Broadband adiabatic inversion pulses for cross-polarization in wideline solid-state nuclear magnetic resonance spectroscopy. J. Magn. Reson. 2012, 224, 38-47.

53. Harris, K. J.; Veinberg, S. L.; Mireault, C. R.; Lupulescu, A.; Frydman, L.; Schurko, R. W. Rapid acquisition of ${ }^{14} \mathrm{~N}$ solid-state NMR spectra with broadband cross polarization. Chem. Eur. J. 2013, 19, 16469-16475.

54. O'Dell, L. A.; Schurko, R. W. QCPMG using adiabatic pulses for faster acquisition of ultra-wideline NMR spectra. Chem. Phys. Lett. 2008, 464, 97-102.

55. O’Dell, L. A.; Rossini, A. J.; Schurko, R. W. Acquisition of ultrawideline NMR spectra from quadrupolar nuclei by frequency stepped WURST-QCPMG. Chem. Phys. Lett. 2009, 468, 330-335.

56. Massiot, D.; Farnan, I.; Gautier, N.; Trumeau, D.; Trokiner, A.; Coutures, J. P. ${ }^{71} \mathrm{Ga}$ and ${ }^{69} \mathrm{Ga}$ nuclear magnetic resonance study of $\beta-\mathrm{Ga}_{2} \mathrm{O}_{3}$ : resolution of four- and six-fold coordinated Ga sites in static conditions. Solid State Nucl. Magn. Reson. 1995, 4, 241-248. 57. Medek, A.; Frydman, V.; Frydman, L. Central transition nuclear magnetic resonance in the presence of large quadrupole couplings: cobalt-59 nuclear magnetic resonance of cobaltophthalocyanines. J. Phys. Chem. A 1999, 103, 4830-4835.

58. Tang, J. A.; Masuda, J. D.; Boyle, T. J.; Schurko, R. W. Ultra-wideline ${ }^{27} \mathrm{Al}$ NMR Investigation of three- and five-coordinate aluminum environments. ChemPhysChem 2006, 7, 117-130.

59. Veinberg, S. L.; Friedl, Z. W.; Harris, K. J.; O’Dell, L. A.; Schurko, R. W. Ultra-wideline ${ }^{14} \mathrm{~N}$ solid-state NMR as a method for differentiating polymorphs: glycine as a case study. CrystEngComm 2015, $17,5225-5236$.

60. Veinberg, S. L.; Friedl, Z. W.; Lindquist, A. W.; Kispal, B.; Harris, K. J.; O’Dell, L. A.; Schurko, R. W. ${ }^{14}$ N Solid-state NMR spectroscopy of amino acids. ChemPhysChem 2016, 17, 4011-4027.

61. Veinberg, S. L.; Johnston, K. E.; Jaroszewicz, M. J.; Kispal, B. M.; Mireault, C. R.; Kobayashi, T.; Pruski, M.; Schurko, R. W. Natural abundance ${ }^{14} \mathrm{~N}$ and ${ }^{15} \mathrm{~N}$ solid-state NMR of pharmaceuticals and their polymorphs. Phys. Chem. Chem. Phys. 2016, 18, 17713-17730. 62. Le Bail, A. Monte Carlo indexing with McMaille. Powder Diffr. 2004, 19, 249-254.

63. David, W. I. F.; Shankland, K.; van de Streek, J.; Pidcock, E.; Motherwell, W. D. S.; Cole, J. C. DASH: a program for crystal structure determination from powder diffraction data. J. Appl. Crystallogr. 2006, 39, 910-915.

64. Larson, A. C.; Von Dreele, R. General Structure Analysis System (GSAS); 2004.

65. Toby, B. H. EXPGUI, a graphical user interface for GSAS. J. Appl. Crystallogr. 2001, 34, 210-213.

66. Iannuzzi, M. Proton transfer in imidazole-based molecular crystals. J. Chem. Phys. 2006, 124, 204710.

67. Summers, M. F. ${ }^{113}$ Cd NMR Spectroscopy of coordination compounds and proteins. Coord. Chem. Rev. 1988, 86, 43-134.

68. Srikanth, K.; Schurko, R. W.; Hung, I.; Ramamoorthy, A. Nuclear magnetic resonance studies of metals in solid state non-metallic materials. Mater. Sci. Technol. 2003, 13, 1191-1196.

69. Frost, J. M.; Kobera, L.; Pialat, A.; Zhang, Y.; Southern, S. A.; Gabindullin, B.; Bryce, D. L.; Murugesu, M. From Discreet Molecule, to polymer, to MOF: mapping the coordination chemistry of $\mathrm{Cd}^{\mathrm{II}} \mathrm{u}$ sing ${ }^{113}$ Cd solid-state NMR. Chem. Comm. 2016, 52, 10680-10683.

70. Kuttatheyil, A. V.; Handke, M.; Bergmann, J.; Lässig, D.; Lincke, J.; Haase, J.; Bertmer, M.; Krautscheid, H. ${ }^{113}$ Cd Solid-State NMR for Probing the Coordination Sphere in Metal-Organic Frameworks. Chem. Eur. J. 2014, 21, 1118-1124.

71. Baxter, E. F.; Bennett, T. D.; Cairns, A. B.; Brownbill, N. J.; Goodwin, A. L.; Keen, D. A.; Cahter, P. A.; Blanc, F.; Cheetham, A. K. A comparison of the amorphization of zeolitic imidazolate frameworks (ZIFs) and aluminosilicate zeolites by ball-milling. Dalton Trans. 2016, 45, 4258-4268.

72. Mennitt, P. G.; Shatlock, M. P.; Bartuska, V. J.; Maciel, G. E. ${ }^{113} \mathrm{Cd}$ Studies of solid cadmium(II) complexes. J. Phys. Chem. 1981, 85, 2087-2091.

73. Jian, F.; Zhao, P.; Wang, S.; Zhang, S. Structure of hexakis(imidazole)cadmium(II) carbonate trihydrate: $\left[\mathrm{Cd}(\mathrm{Im})_{6}\right] \mathrm{CO}_{3} \cdot 3 \mathrm{H}_{2} \mathrm{O} . J$. Chem. Cryst. 2002, 32, 395-398.

74. Lipton, A. S.; Mason, S. S.; Reger, D. L.; Ellis, P. D. ${ }^{113}$ Cd Shielding tensors of monomeric cadmium compounds containing nitrogen donor atoms. 1. CP/MAS Studies on cadmium poly(pyrazolyl)borate complexes having $\mathrm{N}_{4}$ and $\mathrm{N}_{6}$ coordination environments. J. Am. Chem. Soc. 1994, 116, 10182-10187.

75. Wasylishen, R. E. In NMR Spectroscopy Techniques - Practical Spectroscopy; Bruch, M. D., Ed.; Marcel Dekker, Inc.: New York, 1996; pp 105-144.

76. Serpell, C. J.; Beer, P. D. Intermolecular interactions in bromo-, methyl-, and cyanoimidazole derivatives. Cryst. Growth Des. 2013, $13,2866-2871$ 
NMR-ENHHANCED CRYSTALLOGRAPHY

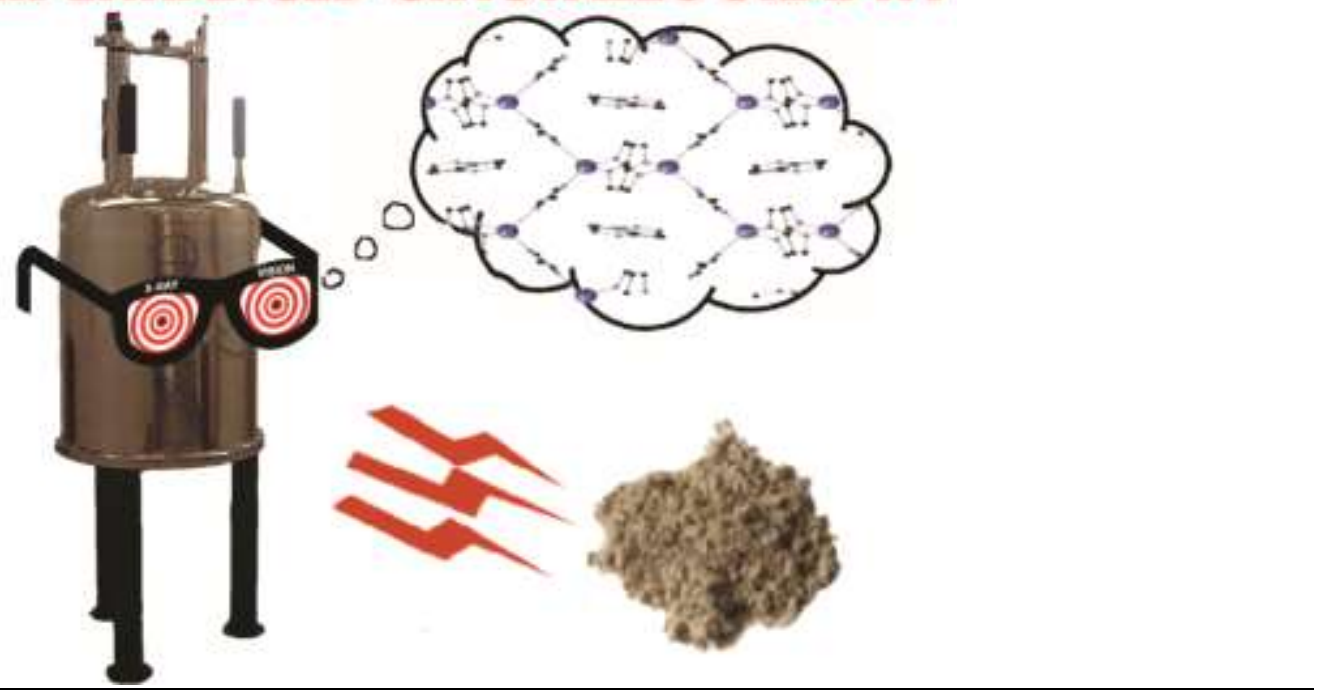

